\title{
Minor Salivary Gland Carcinoma
}

National Cancer Institute

\section{Source}

National Cancer Institute. Minor Salivary Gland Carcinoma. NCI Thesaurus. Code C5957.

A carcinoma that arises from the minor salivary glands. Representative examples include adenoid cystic carcinoma, acinic cell carcinoma, polymorphous low grade adenocarcinoma, and mucinous adenocarcinoma. 